\section{Birth by cesarean delivery and central adiposity in adolescents from a birth cohort}

\section{Nascimento por parto cesáreo e adiposidade central em adolescentes de uma coorte de nascimentos}

\section{Nacimiento por parto con cesárea y adiposidad central en adolescentes de una cohorte de nacimientos}

\author{
Joana D'Arc Matos França de Abreu 1 \\ Sterffeson Lamare Lucena de Abreu 1 \\ Maylla Luanna Barbosa Martins Bragança 1,2 \\ Lilian Fernanda Pereira Cavalcante 1 \\ Ana Karina Teixeira da Cunha França 1 \\ Cecília Claudia Costa Ribeiro 1 \\ Fernando Lamy Filho 1
}

doi: 10.1590/0102-311X00033320

\begin{abstract}
The aim of this study was to analyze the association between birth by cesarean section and central adiposity in adolescents in São Luis, Maranhão State, Brazil. This was a cohort study that included 601 participants evaluated at birth and at 18-19 years. At birth we assessed type of delivery, maternal education, family income, maternal marital status, maternal body mass index before pregnancy, prenatal care, maternal smoking habit, gestational age at delivery and intrauterine growth restriction. In the adolescents, we evaluated central adiposity using the dual X-ray energy absorptiometry method. The indicators of central fat used were the trunk-to-total fat mass ratio $(T / T)$, the android-to-gynoid fat mass ratio $(A / G)$, the trunk-to-limb fat mass ratio $(T / L b)$, and the trunk-to-leg fat mass ratio $(T / L g)$. A theoretical model for the study of associations was developed using directed acyclic graphs, which allowed selecting the variables that required minimum adjustment for inclusion in the predictive model of exposure to cesarean delivery. The data were analyzed with marginal structural models weighted by the inverse of the probability of selection. A total of $38.6 \%$ of the adolescents studied were delivered by cesarean section. There was no significant difference in the central adiposity of adolescents delivered by cesarean section according to the indicators used: $T / T$ ( coefficient $=-0.003 ; 95 \%$ CI: $-0.013 ; 0.007), A / G$ (coefficient $=0.001$; 95\%CI: $-0.015 ; 0.018$ ); $\mathrm{T} / \mathrm{Lb}$ (coefficient $=-0.016 ; 95 \% \mathrm{CI}:-0.048 ; 0.016$ ); $T / L g$ (coefficient $=0.014 ; 95 \% C I:-0.060 ; 0.030$ ). In conclusion, there was no association between cesarean section delivery and greater central adiposity in the studied adolescents.
\end{abstract}

Cesarean Section; Adiposity; Adolescent

\section{Correspondence}

M. L. B. M. Bragança

Universidade Federal do Maranhão.

Rua Barão de Itapary 155, São Luís, MA 65020-070, Brasil.

mayllabmartins@gmail.com

1 Universidade Federal do Maranhão, São Luís, Brasil.

2 Universidade Federal do Tocantins, Palmas, Brasil. 


\section{Introduction}

While body fat is an important indicator of overweight-related diseases, the location of such fat seems to be of greater significance 1. The accumulation of adipose tissue in the central region of the body compared to peripheral fat is more closely associated with an increase in chronic noncommunicable diseases 2 . This is because central fat, due to its visceral component, undergoes lipolysis more easily, releasing greater amounts of inflammatory lipids and adipokines into the bloodstream 3 .

Cross-sectional 4 and longitudinal studies 5,6 have previously assessed the effects of birth by cesarean delivery on obesity in adolescence. One of the possible mechanisms proposed for this association is that nonvaginal birth could cause unfavorable changes in the intestinal microbiota 7 . This change would lead to intestinal dysbiosis, which could affect metabolism and energy storage and thus be considered a link between genetics and the environment in the development of excess weight 8 .

In addition to the intestinal dysbiosis mechanism, the response to physiological stress elicited in the mother and child during and after vaginal birth could serve as a programming event that contributes to the body mass later in life. This can be explained by the stress response in the mother and child caused by vaginal birth, which leads to a more pronounced increase in plasma levels of stress-related hormones such as norepinephrine, cortisol, adrenaline, prolactin, thyroid stimulating hormone, thyroxine and triiodothyronine. The lack or reduced release of these hormones during cesarean delivery could contribute to adiposity throughout life 9 .

Previous systematic reviews and meta-analyses have also shown an association between caesarean delivery and obesity 10,11,12. However, in 2015, a meta-analysis suggested that it is highly likely that caesarean delivery is associated with an increased risk of overweight and obesity due to confounding factors such as sex, maternal weight before pregnancy, gestational diabetes, breastfeeding and the use of antibiotics 13 .

Thus, studying the association between birth by cesarean delivery and central adiposity is important because, despite the reduction in the number of cesarean deliveries in Brazil 14, the prevalence of this method remains high (around 50\% in recent years - Brazilian Health Informatics Department. http://www2.datasus.gov.br/DATASUS/index.php?area=0205) and well above the 15\% percentage recommended by the World Health Organization (WHO) 15 . Few studies have analyzed the association between caesarean delivery and central adiposity. In addition, studies on this topic have used anthropometric measurement methods, such as skinfolds and waist and hip circumference 16,17. To the best of our knowledge, there are no studies on cesarean delivery and the assessment of central adiposity by dual X-ray energy absorptiometry (DXA), which is considered a more accurate method for evaluating fat distribution that allows the use of various indicators of central adiposity 18 .

There are also no studies on this topic that analyze other confounders, such as maternal body mass index before pregnancy, maternal smoking habit and breastfeeding. Additionally, the type of analysis used is crucial for obtaining the results; thus, the use of directed acyclic graphs 19 , the minimal adjustment of variables to avoid confounding bias 20 and analysis using the inverse of the probability of selection.

As such, the aim of this study is to investigate the association between birth by caesarean delivery and central adiposity in adolescents from a birth cohort in São Luís, Maranhão State, Brazil.

\section{Methods}

\section{Study population and sample}

This is a prospective cohort study conducted in the city of São Luís. The cohort was recruited in 1997-1998. In 1996, 96.3\% of the births in this city were in-hospital, and all units with more than 100 births per year were selected to participate in the study. Among the 20,092 births, we randomly selected 2,831 births to mothers residing in the municipality. Of these, twins and stillbirths were excluded, resulting in a sample of 2,691 participants. A search for the participants was carried out in 2016, when the children were adolescents (18-19 years), via public enrollment records in schools or universities, addresses and telephone numbers recorded during the first and second phases of the 
cohort study, military enlistment records for boys, and social media. Approximately 60 to $70 \%$ of the birth cohort, i.e., 1,440 to 1,680 adolescents, were expected to participate in this phase. However, only 601 adolescents who participated in the first phase of the study were located and evaluated for body fat using DXA.

\section{Inclusion and exclusion criteria}

The inclusion criteria were participation of the birth cohort in São Luís, from 1997 to 1998, with information on the type of delivery and consequent reassessment in 2016 using anthropometric measures and DXA. The exclusion criteria were twinship, not having information about the type of delivery, adolescents with plaster or prostheses, pregnant women or adolescents in the postpartum period.

\section{Maternal and perinatal variables}

Maternal and perinatal characteristics were collected via interview with the mother immediately after birth. The following variables were used: family income in minimum wages (up to 1,1 to 3 and more than 3 minimum wages); maternal schooling in years of study (0-4, 5-8, 9-12, over 12 years); maternal smoking habit during pregnancy (yes when the mother smoked at least one cigarette per day and no when the mother did not smoke), maternal body mass index (BMI) before pregnancy as a continuous variable (in $\mathrm{kg} / \mathrm{m}^{2}$ ), age of the mother as a continuous variable (in years), gestational age (in months), sex of the child (male or female), low birth weight according to the WHO definition (less than 2,500g), maternal breastfeeding (yes or no), type of childbirth care (public health care provider; public/private/ philanthropic health care provider; network-affiliated health care provider; autonomous health care provider), marital status of the mother (married, consensual union, or without partner), prenatal care (yes or no) and intrauterine growth restriction (IGR) was determined on the basis of birth weight ratio, which is the ratio between the child's birth weight and the mean weight for sex and gestational age in weeks 21 in accordance with the reference curve of Williams et al. 22. For the current study, a birth weight ratio under 0.85 was defined as IGR and a birth weight ratio over 0.85 as non-IGR 21,23.

Trained individuals measured the weight and length of the newborn immediately after delivery. The infants were weighed on scales that were calibrated weekly to a precision of $10 \mathrm{~g}$.

\section{Anthropometric measurements and DXA}

In 2016, adolescents were invited to visit the collection site, where questionnaires were administered, and clinical and physical examinations were carried out. Data were collected by health professionals, and all professionals underwent training on each instrument they applied in this study.

For the measurements of body composition, we used DXA with a Prodigy Lunar scanner (GE Healthcare, Chicago, USA). All selected data were analyzed using the enCORE software (https:// www.encore.com/).

The DXA examination was performed by a trained technician using the protocol described in the instrument's documentation. During the exam, the adolescent was asked to wear light and tight Lycra clothing - typically training shorts, and sports bras for women - and to lie down on the table in supine position and remain motionless during the scan.

After the whole body scan, the program provided estimates of the fat, bone and lean mass for the whole body and specific regions (trunk, gynoid, android, arms and legs); the percentage of total fat mass, the percentage of trunk fat mass, the percentage of android and gynoid fat mass, the fat mass index (FMI) in $\mathrm{kg} / \mathrm{m}^{2}$ and the ratios between the fat masses of the following regions: trunk/total (T/T), android/gynoid (A/G), trunk/legs (T/Lg), and trunk/limbs (T/Lb) (arms and legs) 1 .

The body mass in kilograms was obtained using a Filizola scale (São Paulo, Brazil), and the height of the adolescents was obtained using the Alturexata stadiometer (Belo Horizonte, Brazil). BMI is calculated as weight $(\mathrm{kg}) /$ height squared $\left(\mathrm{m}^{2}\right)$. In this study, the centrally distributed adipose tissue was used as a response variable. 


\section{Directed acyclic graphs}

A theoretical model of causality was developed using a directed acyclic graph (DAG), which is a theoretical, logical, nonparametric and nonstatistical model established graphically using the public-domain DAGitty software v. 3.0 (http://www.dagitty.net/) 19. The DAG originated in Bayesian networks; it includes variables that could potentially cause biases in the main relationship and also establishes cause and effect relationships between them, as expressed by arrows (Figure 1).

In this model, a relationship between two variables is examined to establish not only a statistical association but a greater approximation of the cause-and-effect relationship between them. The DAG encodes a qualitative theory or assumptions about the causal structure of a problem. Through heuristic rules, the back-door criterion is used to identify the minimum set of variables necessary to adjust confounding bias. The program suggests adjusting only for confounders to avoid the error of possible adjustments of colliders and descendants of colliders 20.

A graphical model was constructed with variables that are generally considered confounders when studying the association between cesarean delivery and adiposity. The software applied algo-

\section{Figure 1}

Directed Acyclic Graph - theoretical model of the association between birth by cesarean delivery and central adiposity.



BMI: body mass index; IGR: Intrauterine growth restriction; NB: newborn.

Note: exposure variable: birth by cesarean section; outcome variable: central adiposity; gray circle: unobserved variable; blue circle: ancestor of outcome; red circle: ancestor of exposure and outcome; green line: causal path; red line: biasing path. 
rithms and established which variables in the predictive model of exposure should be adjusted in the subsequent statistical analysis.

\section{Statistical analysis and data processing}

Losses to follow-up were evaluated using the chi-square and Mann-Whitney tests to identify variables that exhibited significant differences relative to birth method. Logistic regression generated a weight for each participant to weight the final sample in relation to sample losses. The variables used to weight for sample loss were maternal education, maternal age, family income at birth, childbirth care, type of delivery, sex of the adolescent and prenatal care.

The following ratios were used as measures of central adiposity: trunk/total (T/T); android/ gynoid (A/G), trunk/limbs (the fat mass in the trunk over the sum of the fat mass in the arms and legs) $(\mathrm{T} / \mathrm{Lb})$ and trunk/legs $(\mathrm{T} / \mathrm{Lg})$, based on the measurements obtained by the DXA examination. Normality cut-off points were not found in the literature for these ratios in similar populations and or the same age range of the participants 24 .

The variables selected for minimum adjustment by the DAGitty software were intrauterine growth restriction, gestational age at delivery, maternal education, maternal smoking habit, maternal age, maternal BMI before pregnancy, prenatal care, family income at birth and maternal marital status.

An epidemiological causal inference analysis method was used. The estimates were obtained by weighting the inverse of the probability of selection to eliminate bias from the differences in the distribution of the variables in the exposed (adolescents delivered by cesarean) and unexposed (adolescents not delivered by cesarean) groups. In this type of analysis, the adolescents with a higher probability of being selected as exposed had a lower weight than those with a lower probability of selection, who had a higher weight. This analysis seeks a closer approximation of causality when comparing different situations in the same individual. Thus, the adolescent is analyzed as part of the exposed and unexposed groups. The data and estimates contribute to an estimation of the non-observed data, enabling estimates to be obtained without confounding bias 25,26 .

In causal inference analysis, observational studies are treated as if they were experimental with conditional randomization to balance the groups (exposed and unexposed), resulting in permutability between them. Permutability occurs when the balance is effective between the variables that predict the outcomes of the groups. To verify whether permutability between the exposure groups was achieved, the standardized difference of 0 (with values under 0.2 being acceptable) was considered an indicator of good permutability between groups, as was the ideal variance ratio of 1 (with values between 0.8 and 1.2 being acceptable). In addition, another tebalance overid routine was performed to check for the presence of balancing by "overidentification", and adequate balancing was determined when the p-value was greater than 0.0525 . The level of significance was set at $5 \%$. The data were analyzed using Stata version 14.0 (https://www.stata.com).

\section{Ethical and legal aspects}

All participants signed the informed consent form. The study was approved by the Ethics Research Committee of the University Hospital of Federal University of Maranhão (UFMA), Brazil, under opinion n. 3104-476/2005.

\section{Results}

In this study, a total of 601 adolescents were evaluated. It was possible to verify that the adolescents who returned to assess their body composition with DXA were mostly male (odds ratio - OR $=0.67$; 95\%CI: $0.55 ; 0.80$ ), those with mothers who had 9 and 12 years of schooling in 1997/1998 (OR = 1.44; $95 \% \mathrm{CI}: 1.07 ; 1.95)$ and those whose mother had performed prenatal care $(\mathrm{OR}=1.69$; 95\%CI: 1.41 ; 2.50) (Table 1). 
Table 1

Logistic regression of socioeconomic and maternal perinatal characteristics for sample weights for follow-up losses. São Luís, Maranhão State, Brazil 1997/1998 and 2016.

\begin{tabular}{|c|c|c|}
\hline \multirow[t]{2}{*}{ Variables } & \multicolumn{2}{|c|}{ Weighting for loss of follow-up } \\
\hline & OR & $95 \% \mathrm{Cl}$ \\
\hline \multicolumn{3}{|l|}{ Maternal schooling level (years) } \\
\hline $5-8$ & 1.16 & $0.87 ; 1.54$ \\
\hline $9-12$ & 1.44 & $1.07 ; 1.95$ \\
\hline$>12$ & 0.95 & $0.54 ; 1.67$ \\
\hline Ignored & 0.65 & $0.08 ; 5.47$ \\
\hline \multicolumn{3}{|l|}{ Family income at birth (minimum wage) } \\
\hline $1-3$ & 0.88 & $0.70 ; 1.10$ \\
\hline Up to 1 & 0.76 & $0.56 ; 1.03$ \\
\hline Ignored & 0.80 & $0.53 ; 1.19$ \\
\hline \multicolumn{3}{|l|}{ Childbirth care } \\
\hline Public/Private/Philanthropic health care provider & 0.96 & $0.78 ; 1.18$ \\
\hline Network-affiliated health care provider & 1.03 & $0.71 ; 1.48$ \\
\hline Autonomous health care provider & 0.41 & $0.14 ; 1.22$ \\
\hline Type of delivery & 1.19 & $0.96 ; 1.47$ \\
\hline Sex of the adolescent & 0.67 & $0.55 ; 0.80$ \\
\hline Maternal age & 1.01 & $0.99 ; 1.03$ \\
\hline Prenatal care & 1.69 & $1.14 ; 2.50$ \\
\hline
\end{tabular}

95\%Cl: 95\% confidence interval; OR: odds ratio.

Note: participants number: 2,691. Reference categories: maternal schooling level (0-4 years), family income at birth (more than 3 minimum wages), childbirth care (public health care provider), type of delivery (vaginal birth), sex of the adolescent (male), maternal age (15 to 19 years), prenatal care (absence).

Of the total number of adolescents evaluated, $38.6 \%$ were born by cesarean section, $62.6 \%$ were male, $84.8 \%$ were breastfed by their mothers, $13 \%$ had intrauterine growth restriction, $11 \%$ were born preterm, $8.5 \%$ born with low birth weight and $50 \%$ of their families earned more than three minimum wages. The most births occurred by public health care provider $(58.1 \%)$ and prenatal care was received in $94 \%$ of pregnancies. Among the mothers of the adolescents, the most prevalent age range was between 20 and 24 years (38\%), $42 \%$ had 9 to 12 years of study, the most common marital status was consensual union (48\%), 4.8\% reported smoking during pregnancy. Maternal BMI was on average $21 \mathrm{~kg} / \mathrm{m}^{2} ; 16 \%$ of the mothers had a low weight, $9 \%$ had overweight and $1 \%$ had obesity (data not shown in Table).

Regarding body composition and fat distribution measurements in adolescents, it was observed that female adolescents had a higher average for total fat mass $(19.5 \mathrm{~kg})$, trunk fat mass $(8,641.02 \mathrm{~g})$, limbs fat mass $(10,049.92 \mathrm{~g})$, legs fat mass $(7,894.20 \mathrm{~g})$, android fat mass $(7,894.20 \mathrm{~g})$, gynoid fat mass $(3,763.04 \mathrm{~g})$ and FMI $\left(7.59 \mathrm{~kg} / \mathrm{m}^{2}\right)$ (Table 2$)$.

The observed variables (IGR, gestational age, maternal education, maternal age, maternal smoking habit, maternal BMI before pregnancy, prenatal care, family income at birth, maternal marital status) were equally distributed between groups of adolescents who were born by cesarean section and who were born by normal delivery. All absolute differences in means were less than 0.2 standard deviation and all variance ratios were between 0.08 and 1.2 (Table 4). Thus, the observed variables were equally balanced between the groups (Table 3). 
Table 2

Body composition and fat distribution measurements in adolescents and maternal BMI according to the sex of adolescents. São Luís, Maranhão State, Brazil, 1997/1998 and 2016.

\begin{tabular}{|c|c|c|c|}
\hline Variables & $\begin{array}{c}\text { Male } \\
(\mathrm{n}=376) \\
\text { Mean + SD }\end{array}$ & $\begin{array}{c}\text { Female } \\
(n=225) \\
\text { Mean + SD }\end{array}$ & $\begin{array}{c}\text { Total } \\
(n=601) \\
\text { Mean + SD }\end{array}$ \\
\hline Maternal BMI (kg/m²) & $21.17+2.85$ & $21.08+3.11$ & $21.14+2.95$ \\
\hline Adolescents' height (m) & $1.73+0.08$ & $1.60+0.06$ & $1.68+0.95$ \\
\hline Adolescents' body weight $(\mathrm{kg})$ * & $64.96+12.30$ & $55.72+11.80$ & $61.50+12.90$ \\
\hline Adolescents' BMI (kg/m²) & $21.77+3.64$ & $21.70+4.05$ & $21.74+3.79$ \\
\hline Total fat mass $(\mathrm{kg})$ * & $13.94+7.15$ & $19.50+7.40$ & $16.04+7.70$ \\
\hline Trunk fat mass $(\mathrm{g})$ * & $6,035.41+3,880.01$ & $8,641.02+3,816.27$ & $7,017.42+4,054.87$ \\
\hline Limbs fat mass $(g)$ * & $7,021.72+3,369.96$ & $10,049.92+3,677.26$ & $8163.00+3782.67$ \\
\hline Legs fat mass $(\mathrm{g})$ * & $5,439.16+2,573.86$ & $7,894.20+2,877.15$ & $6,364.43+2,941.57$ \\
\hline Android fat mass (g) * & $810.43+664.11$ & $1,187.43+648.08$ & $952.51+682.52$ \\
\hline Gynoid fat mass (g) * & $2,319.70+1,299.93$ & $3,763.04+1,347.52$ & $2,863.68+1,491.44$ \\
\hline Trunk/total ratio $(\mathrm{T} / \mathrm{T})$ & $0.41+0.05$ & $0.43+0.05$ & $0.42+0.05$ \\
\hline Android/gynoid ratio (A/G) & $0.32+0.09$ & $0.30+0.08$ & $0.31+0.09$ \\
\hline Trunk/limbs (T/Lb) & $0.83+0.20$ & $0.85+0.15$ & $0.83+0.18$ \\
\hline Trunk/legs (T/Lg) & $1.07+0.27$ & $1.08+0.21$ & $1.07+0.25$ \\
\hline Fat mass index $\left(\mathrm{kg} / \mathrm{m}^{2}\right)$ * & $4.69+2.40$ & $7.59+2.73$ & $5.79+2.90$ \\
\hline
\end{tabular}

A/G: android-to-gynoid fat mass ratio; BMI: body mass index; SD: standard deviation; T/Lb: trunk-to-limb fat mass ratio; T/Lg: trunk-to-leg fat mass ratio; T/T: trunk-to-total fat mass ratio.

* $\mathrm{p}$-value $<0.05$.

Table 3

Balancing the covariates by the inverse of the probability of selection. Difference between standardized means and variance ratios.

\begin{tabular}{|c|c|c|c|c|}
\hline \multirow[t]{2}{*}{ Variáveis } & \multicolumn{2}{|c|}{ Difference between standard averages * } & \multicolumn{2}{|c|}{ Variance ratio ** } \\
\hline & Crude estimate & Weighted estimate & Crude estimate & Weighted estimate \\
\hline Intrauterine growth restriction & -0.05 & -0.020 & 0.90 & 0.96 \\
\hline Gestational age at birth & -0.06 & 0.003 & 0.85 & 1.00 \\
\hline Maternal education_2 & -0.48 & 0.024 & 0.72 & 1.01 \\
\hline Maternal education_3 & 0.21 & -0.013 & 1.01 & 1.00 \\
\hline Maternal education_4 & 0.45 & -0.011 & 9.50 & 0.95 \\
\hline Maternal age & 0.50 & -0.061 & 1.35 & 1.02 \\
\hline Maternal smoking & 0.01 & 0.005 & 0.94 & 0.97 \\
\hline Maternal prepregnancy BMI & 0.19 & -0.030 & 1.13 & 0.82 \\
\hline Prenatal care & 0.01 & 0.016 & 0.93 & 0.84 \\
\hline Family income at birth_2 & -0.25 & -0.002 & 0.81 & 1.00 \\
\hline Family income at birth_3 & -0.24 & 0.070 & 0.56 & 1.17 \\
\hline Family income at birth_4 & -0.06 & 0.040 & 0.76 & 1.20 \\
\hline Maternal marital status_2 & -0.35 & 0.028 & 0.94 & 1.00 \\
\hline Maternal marital status_3 & -0.16 & -0.007 & 0.78 & 0.99 \\
\hline
\end{tabular}

BMI: body mass index.

* Values close to 0 (zero) indicate similarity between groups;

** Values close to 1 (one) indicate similarity between groups. 
Table 4

Effect of cesarean delivery on the body fat distribution of male and female adolescents, weighted by the inverse of the probability of selection and for sample losses. São Luís, Maranhão State, Brazil, 1997/1998 and 2016.

\section{Body fat distribution}

Coefficient

Trunk-to-total fat mass ratio (T/T)

Male

Female

Total

Android-to-gynoid fat mass ratio (A/G)

\section{Male}

Female

Total

Trunk-to-limb fat mass ratio (T/Lb)

Male

Female

Total

Trunk-to-leg fat mass ratio (T/Lg)

Male

Female

Total

Fat mass index

Male

Female

Total

Trunk fat mass

Male

Female

Total

Android fat mass

Male

Female

Total

Gynoid fat mass

Male

Female

Total

Total fat mass

Male

Female

Total

Body mass index

Male

Female

Total
Cesarean delivery

$95 \% \mathrm{Cl}$

$\begin{array}{ll}<-0.001 & -0.013 ; 0.011 \\ -0.006 & -0.002 ; 0.007 \\ -0.003 & -0.013 ; 0.007 \\ & \\ 0.005 & -0.014 ; 0.024 \\ -0.009 & -0.030 ; 0.015 \\ 0.001 & -0.015 ; 0.018\end{array}$

$-0.014$

$-0.050 ; 0.030$

-0.070; 0.020

$-0.048 ; 0.016$

$-0.009$

$-0.060 ; 0.460$

$-0.090 ; 0.030$

$-0.060 ; 0.030$

$-0.620 ; 0.660$

$-0.830 ; 0.780$

$-0.774 ; 0.520$

$-0.030 ; 0.020$

$-0.030 ; 0.030$

$-0.030 ; 0.020$

$-0.002$

$-0.030 ; 0.020$

$-0.004$

$-0.040 ; 0.030$

$-0.030 ; 0.020$

$-0.002$

$-0.030 ; 0.020$

0.004

$-0.007$

-0.020; 0.030

$-0.036 ; 0.021$

$<-0.001$

$-0.020 ; 0.020$

$-0.020 ; 0.030$

$-0.025 ; 0.019$

$-0.003$

$-0.670 ; 1.070$

0.200

$-1.260 ; 0.910$

$-0.800 ; 0.740$

95\%Cl: 95\% confidence interval. 
There were no significant differences in the central adiposity indicators evaluated by DXA: T/T (coefficient $=-0.003 ; 95 \% \mathrm{CI}:-0.013 ; 0.007), \mathrm{A} / \mathrm{G}$ (coefficient $=0.001 ; 95 \% \mathrm{CI}:-0.015 ; 0.018) ; \mathrm{T} / \mathrm{Lb}$ (coefficient $=-0.016 ; 95 \% \mathrm{CI}:-0.048 ; 0.016)$ and $\mathrm{T} / \mathrm{Lg}$ (coefficient $=-0.014 ; 95 \% \mathrm{CI}=-0.060 ; 0.030$ ). There were also no differences between adolescents born by vaginal delivery or caesarean section in the percentages of fat mass in the trunk (coefficient $=-0.005 ; 95 \% \mathrm{CI}:-0.030 ; 0.020$ ), android (coefficient $=-0.007 ; 95 \% \mathrm{CI}:-0.036 ; 0.021)$ and gynoid (coefficient $=-0.007 ; 95 \% \mathrm{CI}:-0.036 ; 0.021)$ regions or in the measurements of BMI (coefficient $=-0.026$; $95 \% \mathrm{CI}$ : -0.080 ; 0.074) and FMI (coefficient $=$ -0.127 ; 95\%CI: -0.774 ; 0.520) (Table 4).

There were no differences between adolescents born by vaginal delivery or cesarean section in $\mathrm{T} / \mathrm{T}$ (coefficient $=-0.003 ; 95 \% \mathrm{CI}:-0.013 ; 0.007), \mathrm{A} / \mathrm{G}$ (coefficient $=0.001 ; 95 \% \mathrm{CI}:-0.015 ; 0.018), \mathrm{T} / \mathrm{Lb}$ (coefficient $=-0.016 ; 95 \% \mathrm{CI}:-0.048 ; 0.016), \mathrm{T} / \mathrm{Lg}$ (coefficient $=-0.014 ; 95 \% \mathrm{CI}:-0.060 ; 0.030$ ), trunk fat mass (coefficient $=-0.005 ; 95 \%$ CI: $-0.030 ; 0.020$ ), android fat mass (coefficient $=-0.007 ; 95 \%$ CI: $-0.036 ; 0.021$ ), gynoid fat mass (coefficient $=-0.007 ; 95 \% \mathrm{CI}:-0.036 ; 0.021$ ), total fat mass (coefficient $=$ -0.003 ; 95\%CI: $-0.025 ; 0.019)$, BMI (coefficient $=-0.026 ; 95 \%$ CI: $-0.080 ; 0.074)$ and FMI (coefficient $=$ $-0.127 ; 95 \% \mathrm{CI}:-0.774 ; 0.520$ ). If there were significant differences between adolescents born by vaginal delivery or cesarean section in the central and total adiposity, the magnitude of the effects would be very small. For example, if the adolescents had been born by cesarean delivery, their BMI would reduce by $0.026 \mathrm{~kg} / \mathrm{m}^{2}$ and their total fat mass would reduce by $0.003 \mathrm{~g}$ (Table 4 ).

\section{Discussion}

Our results showed no association between birth by cesarean delivery and higher amounts of central and total adiposity in adolescents aged 18 and 19 years old from the city of São Luís.

This study has some strengths. Few studies have evaluated the association among cesarean delivery and central body fat distribution. To date, no other studies have assessed cesarean section and central adiposity using DXA to evaluate central adiposity. This method of central adiposity assessment evaluates it more accurately than anthropometric measurements. Another strength is the cohort study design, which followed the participants from birth. Weighting the inverse of the probability of participation in the follow-up attenuated the identification of spurious correlations due to the losses to follow-up that occurred in this cohort during the follow-up of adolescence. The predictive model of birth by cesarean delivery with DAG-based adjustments reduced the chance of confounding bias and allowed verification of the permutability between the exposed and unexposed groups (balancing), and the analysis by marginal structural models weighted by the inverse of the probability of exposure allowed an estimation closer to the causal effect of birth by cesarean delivery on central adiposity.

Among the limitations of this study is the lack of data on the therapeutic indication for cesarean section, as indications due to gestational diabetes and eclampsia may have a stronger relationship with adiposity in adolescents. Another limitation is that the measurement of android abdominal fat by DXA does not allow for distinguishing between the visceral and subcutaneous tissues of the abdomen unless the visceral adipose tissue is evaluated. However, other indicators evaluated by DXA were used to analyze central adiposity, and these are more accurate than anthropometric measurements because they are able to measure the fat mass separately from the lean body mass 1 .

Two previous studies were conducted with male individuals in late adolescence, verifying an association among cesarean delivery and obesity measured by BMI: Bar-Meir et al. 27 evaluated 17,003 17-year-olds individuals in West Jerusalem, and Svensson et al. 28 studied 21,051 18-year-old individuals in Denmark. Two other studies were found that did not verify this association: Barros et al. 5 who studied fat mass index assessed by DXA in 3961 adolescents aged 18 years in the city of Pelotas in Rio Grande do Sul, Brazil, and the study by Ahlqvist et al. ${ }^{29}$ who studied BMI in 97,291 men with an average age of 18 years from Sweden. These studies do not point to a consensus.

Some meta-analyses were performed to elucidate the issue, but they continued to emphasize the complexity of the question because they found discordant results. These meta-analyses concluded that there was an association between cesarean delivery and obesity in childhood 11, in adolescents 10 and in adulthood 12. However, in the meta-analysis of Sutharsan et al. 13 it was suggested that the association between overweight and obesity is due to the influence of confounding factors such as 
sex, maternal weight before pregnancy, gestational diabetes, maternal breastfeeding and the use of antibiotics 13 . In our study, these confounding variables were present in the initial predictive model.

Studies carried out on individuals in their late adolescence found an association even after adjusting for several confounding factors 27,28. However, none of them adjusted for pregestational BMI, although Bar-Meir et al. 27 verified interaction between quartiles of pregestational BMI and observed significant association between cesarean section and obesity only among offspring born to mothers in the highest quartile of pregestational BMI.

According to Gillman \& Ludwig 30, the determinants of the development of obesity are numerous and the maternal nutritional status prior to birth is one of them. The higher pregestational maternal BMI may contribute to obesity in people born to mothers with overweight and obesity. This can be explained by genetic risk or by intestinal transmission of the mother's obesogenic microbiota during delivery 12 . This hypothesis is supported by a study that found that overweight pregnant women and women with gestational weight gain greater than $16 \mathrm{~kg}$ had higher concentrations of Bacterioides, Clostridium and Staphylococcus 31. Consequently, the genetic characteristics or the gestational exposure of children born from overweight and obese mothers may make them less able to recover from any risk of obesity caused by cesarean delivery 30 .

Most studies on the association between cesarean delivery and obesity have been done including children 4,5,6,17,32,33,34,35,36,37,38 and adults 5,16,39,40,41. Some studies have been carried out including adolescent individuals $4,5,6,17,42$, but there are few studies conducted with individuals in their late adolescence 4,5,27,29. This study was carried out with people in this age group because they have already gone through the growth stage and are no longer under the hormonal effects of adolescence, which provide greater deposition of adipose tissue 43 . Thus, adiposity and its distribution in late adolescents may be more related to the risk factors to which these adolescents were exposed.

It is plausible that the effect of cesarean delivery on obesity is influenced by a wide range of factors 13 . It is likely that different methods, especially regarding the type of measurement and outcome used, may have contributed to the identification of associations among cesarean delivery and body fat in other studies. Two studies conducted with adolescents aged 17 and 18 using BMI found an association 27,28. Only one study was found using DXA to assess fat mass index and found no association. No study was found to assess central adiposity in late adolescence. It is noteworthy that the assessment of total and central adiposity using DXA is accurate and may have contributed to our results. Even though the use of BMI and waist circumference are anthropometric methods commonly used for their simplicity, ease of execution, low cost and reproducibility, they have limitations in predicting the amount of body fat, as they include, in addition to adipose tissue, organs and tissues 44 . In addition, for waist circumference differences in location may occur between studies and this lack of methodological standardization requires caution when comparing results to avoid under or overestimation of prevalence.

The inability to find an association between cesarean section and central adiposity may be due to the methodological advances in this study, namely: the adjustment for pregestational BMI, the use of DXA as a more accurate method to assess adiposity, including individuals who already underwent intense changes as adolescents, and especially the analyses we carried out. The analysis sought a closer approximation to causality when the estimates of birth by cesarean or vaginal delivery were compared in the same adolescent. With this type of analysis, there is a comparison of different situations in the same adolescent, which is analyzed as part of exposed and unexposed groups, with a balance between these two groups 25. In addition, a theoretical causality model based on the DAG was designed to establish a minimum set of variables used for the confounding adjustment to avoid unnecessary adjustments, spurious correlations and estimation errors 20 . The theoretical model included all variables not studied in previous publications (such as sex, maternal weight before pregnancy, gestational diabetes, breastfeeding and the use of antibiotics) and that could contribute to generating spurious correlation, as also indicated in the meta-analysis of Sutharsan et al. 13 .

Our study went further into the question of cesarean delivery and obesity. Besides ours, we did not find any studies with the obtained outcome. We sought to evaluate the association between birth by caesarean delivery and central adiposity using indicators of central adiposity constructed by DXA measurements, such as the $\mathrm{AG}, \mathrm{T} / \mathrm{T}, \mathrm{T} / \mathrm{Lg}$, and $\mathrm{T} / \mathrm{Lb}$ fat ratios, in addition to percentages of fat in the trunk and android fat. This approach was chosen because the accumulation of fat in the trunk has 
been associated with chronic diseases such as diabetes, hypertension, and cardiovascular diseases 1,32. Kouda et al. 45 showed that an increase in the T/Lb fat mass ratio was associated with an increase in blood pressure in adolescents.

In studies that found an association among caesarean delivery and obesity, the hygiene hypothesis is cited as biological plausibility. This hypothesis is based on nonvaginal birth, which causes dysbiosis or an unfavorable change in the intestinal microbiota, leading to implications for obesogenesis 8 . However, this theory is contested by some researchers because an individual's microbiota is a risk factor that can be modified via diet, exercise, use of antibiotics or probiotics or even fecal transplantation 46. This might be one of the reasons why we did not find an association. Thus, we believe that if there was an association between being born by cesarean section and total and central adiposity, it could already manifest itself in individuals in their late adolescence and not just in future ages.

We concluded that there was no association between birth by cesarean delivery and greater central adiposity in adolescents aged 18-19, which may be due to a lack of causal relation.

\section{Contributors}

J. D’A. M. F. Abreu, S. L. L. Abreu, M. L. B. M. Bragança, L. F. P. Cavalcante, A. K. T. C. França, C. C. C. Ribeiro and F. Lamy Filho contributed to the study conception and design, data analysis and interpretation, drafting the article, revising it critically for important intellectual content, and final approval of the version to be published.

\section{Additional informations}

ORCID: Joana D’Arc Matos França de Abreu (00000001-5124-7394); Sterffeson Lamare Lucena de Abreu (0000-0003-1462-6963); Maylla Luanna Barbosa Martins Bragança (0000-0002-64023899); Lilian Fernanda Pereira Cavalcante (00000002-5578-221X); Ana Karina Teixeira da Cunha França (0000-0002-4460-2631); Cecília Claudia Costa Ribeiro (0000-0003-0041-7618); Fernando Lamy Filho (0000-0002-7858-4195).

\section{Acknowledgments}

The Department of Science and Technology of the Brazilian Ministry of Health (DECIT) and the Brazilian National Research Council (CNPq) provided funding for the study (process: 400943/2013-1).

\section{References}

1. Vasan S, Osmond C, Canoy D, Christodoulides C, Neville MJ, Gravio CD et al. Comparison of regional fat measurements by dual-energy $\mathrm{X}$ ray absorptiometry and conventional anthropometry and their association with markers of diabetes and cardiovascular disease risk. Int J Obes 2018; 42: 850-7.

2. Gaston SA, Tulve NS, Ferguson TF. Abdominal obesity, metabolic dysfunction, and metabolic syndrome in U.S. adolescents: National Health and Nutrition Examination Survey 2011-2016. Ann Epidemiol 2019; 30:30-6.

3. uglielmi V, Sbraccia P. Obesity phenotypes: depot-differences in adipose tissue and their clinical implications. Eat Weight Disord 2018; 23:3-14.

4. Wang $\mathrm{ZH}, \mathrm{Xu} \mathrm{RB}$, Dong $\mathrm{YH}$, Yang YD, Wang $\mathrm{S}$, Wang XJ et al. Association between cesarean birth and the risk of obesity in 6-17 year-olds. Zhonghua Liu Xing Bing Xue Za Zhi 2017; 38:1598-602.

5. Barros AJD, Santos LP, Wehrmeister F, Motta JVSM, Matijasevich A, Santos IS et al. Caesarean section and adiposity at 6,18 and 30 years of age: results from three Pelotas (Brazil) birth cohorts. BMC Public Health 2017; 17:256.

6. Yuan C, Gaskins AJ, Blaine AI, Zhang C, Gillman MW, Missmer SA, et al. Association between cesarean birth and risk of obesity in offspring in childhood, adolescence and early adulthood. JAMA Pediatr 2016; 170:e162385. 
7. Mishra AK, Dubey V, Ghosh AR. Obesity: an overview of possible role(s) of gut hormones, lipid sensing and gut microbiota. Metabolism 2016; 65:48-65.

8. Dominguez-Bello MG, De Jesus-Laboy KM, Shen N, Cox LM, Amir A, Gonzalez A et al. Partial restoration of the microbiota of cesarean-born infants via vaginal microbial transfer. Nat Med 2016; 22:250-3.

9. Hyde MJ, Mostyn A, Modi N, Kemp PR. The health implications of birth by Caesarean section. Biol Rev Camb Philos Soc 2012; 87:22943.

10. Li HT, Zhou YB, Liu JM. The impact of cesarean section on offspring overweight and obesity: a systematic review and meta-analysis. Obstet Gynecol Surv 2014; 69:9-11.

11. Kuhle S, Tong OS, Woolcott CG. Association between caesarean section and childhood obesity: a systematic review and meta-analysis. Obes Rev 2015; 16:295-303.

12. Darmasseelane K, Hyde MJ, Santhakumaran S, Gale C, Modi N. Mode of delivery and offspring body mass index, overweight and obesity in adult life: a systematic review and metaanalysis. PLoS One 2014; 9:e87896.

13. Sutharsan R, Mannan M, Mamun AA. Caesarean delivery and the risk of offspring overweight and obesity over the life course: a systematic review and bias-adjusted meta-analysis. Clin Obes 2015; 5:293-301.

14. Leal MC, Bittencourt SA, Esteves-Pereira AP, Ayres BVS, Silva LBRAA, Thomaz EBAF. Avanços na assistência ao parto no Brasil: resultados preliminares de dois estudos avaliativos. Cad Saúde Pública 2019; 35:e00223018.

15. World Health Organization. WHO Statement on Caesarean Section Rates. Geneva: World Health Organization; 2015.

16. Mesquita DN, Barbieri MA, Goldani HA, Cardoso VC, Goldani MZ, Kac G, et al. Cesarean section is associated with increased peripheral and central adiposity in young adulthood: cohort study. PLoS One 2013; 8:e66827.

17. Salehi-Abargouei A, Shiranian A, Ehsani S, Surkan PJ, Esmaillzadeh A. Caesarean delivery is associated with childhood general obesity but not abdominal obesity in Iranian elementary school children. Acta Paediatr 2014; 103:e383-7.

18. Shepherd JA, Bennett KN, Sommer MJ, Heymsfield SB. Body composition by DXA. Bone 2017; 104:101-5.

19. Textor J, Hardt J, Knuppel S. DAGitty: a graphical tool for analyzing causal diagrams. Epidemiology $2011 ; 22: 745$.

20. Cortes TR, Faerstein E, Struchiner CJ. Use of causal diagrams in epidemiology: applicationto a situationwithconfounding. Cad Saúde Pública 2016; 32:e00103115.

21. Kramer MS, Platt R, Yang $H$, McNamara H, Usher HR. Are all growth-restricted newborns created equal(ly)? Pediatrics 1999; 103:599602.
22. Williams RL, Creasy RK, Cunningham GC, Hawes WE, Norris FD, Tashiro M. Fetal growth and perinatal viability in California. Obstet Gynecol 1982; 59:624-32.

23. Silveira PP, Pokhvisneva I, Gaudreau H, Rifkin-Graboi A, Broekman BFP, Steiner M, et al. Birth weight and catch up growth are associated with childhood impulsivity in two independent cohorts. Sci Rep 2018; 8:13705.

24. Imboden MT, Welch WA, Swartz AM, Montoye AH, Finch HW, Harber MP, et al. Reference standards for body fat measures using GE dual energy $x$-ray absorptiometry in Caucasian adults. PLoS One 2017; 12:e0175110.

25. Hernán MA, Hernández-Díaz S, Werler MM, MitchellAA. Causal knowledge as a prerequisite for confounding evaluation: an application to birth defects epidemiology. Am J Epidemiol 2002; 155:176-84.

26. Robins JM. Causal inference. Boca Raton: Chapman \& Hall/CRC Press; 2016.

27. Bar-Meir M, Friedlander Y, Margalit CR, Hochner H. Mode of delivery and offspringadiposity in late adolescence: the modifying role of maternal pre-pregnancy body size. PLoS One 2019; 14:e0209581.

28. Svensson E, Hyde MJ, Modi N, Ehrenstein V. Caesarean section and body mass index among Danish adult men. Obesity 2013; 21:429-33.

29. Ahlqvist VH, Persson M, Magnusson C, Berglind D. Elective and nonelective cesarean section and obesity among young adult male offspring: a Swedish population-based cohort study. PLoS Med 2019; 16:e1002996.

30. Gillman MW, Ludwig DS. How early should obesity prevention start? N Engl J Med 2013; 369: 2173-5.

31. Kalliomaki MC, Salminen S, Isolauri E. Early differences in fecal microbiota composition in children may predict overweight. Am J Clin Nutr 2008; 87:534-8.

32. Goldani MZ, Barbieri MA, da Silva AAM, Gutierrez MRP, Bettiol H, Goldani HAS. Cesarean section and increased body mass index in school children: two cohort studies from distinct socioeconomic background areas in Brazil. Nutr J 2013; 12:104.

33. Azcorra H, Rodríguez L, Banik SD, Bogin B, Varela-Silva MI, Dickinson F. Caesarean birth and adiposity parameters in 6- to 8year-old urban Maya children from two cities of Yucatan, Mexico. Am J Hum Biol 2019; 31:e23217.

34. Cai M, Loy SL, Tan KH, Godfrey KM, Gluckman PD, Chong YS, et al. Association of elective and emergency cesarean delivery with early childhood overweight at 12 months of age. JAMA Netw Open 2018; 1:e185025.

35. Chojnackia RM, Holschera HD, Balbinotb AR, Rainec LB, Biggand JR, Walkg AM et al. Relations between mode of birth delivery and timing of developmental milestones and adiposity in preadolescence: a retrospective study. Early Hum Dev 2019; 129:52-9. 
36. Chu S, Zhang Y, Jiang Y, Sun Y, Zhu Q, Liu S, et al. Cesarean section and risks of overweight and obesity in school-aged children: a population-based study. Int J Med 2018; 111:859-65.

37. Mueller NT, Zhang M, Hoyo C, Østbye T, Benjamin-Neelon SE. Does cesarean delivery impact infant weight gain and adiposity over the first year of life? Int J Obesity 2018; 43:1549-55.

38. Rifas-Shiman SL, Gillman MW, Hawkins SS. Association of cesarean delivery with body mass Index z Score at Age 5 Years. JAMA Pediatr 2018; 172:777-9.

39. Mamun AA, Sutharsan R, O'Callaghan M, Williams G, Najman J, McIntyre HD, et al. Cesarean delivery and the long-term risk of offspring obesity. Obstet Gynecol 2013; 122:1176-83.

40. Chavarro JE, Martín-Calvo N, Yuan C, Arvizu M, Rich-Edwards JW, Michels KB, et al. Association of birth by cesarean delivery with obesity and type 2 diabetes among adult women. JAMA 2020; 3:e202605.

41. Hansen S, Halldorsson TI, Olsen SF, Rytter D, Bech BH, Granström C, et al. Birth by cesarean section in relation to adult offspring overweight and biomarkers of cardiometabolic risk. Int J Obes 2018; 42:15-9.
42. Zhou Y, Zhang Y, Sun Y, Zhang D. Association of cesarean birth with body mass index trajectories in adolescence. Int J Environ Res Public Health 2020; 17:2003.

43. Palmer BF, Clegg DJ. The sexual dimorphism of obesity. Mol Cell Endocrinol 2015; 15:1139.

44. Javed A, Jumean M, Murad MH, Okorodudu D, Kumar S, Somers VK, et al. Diagnostic performance of body mass index to identify obesity as defined by body adiposity in children and adolescents: a systematic review and meta-analysis. Pediatr Obes 2015; 10:234-44.

45. Kouda K, Nakamura H, Fujita Y, Ohara K, Iki $M$. Increased ratio of trunk to appendicular fat and increased blood pressure. Circ J 2012; 76:2848-54.

46. Nicholson JK, Holmes E, Kinross J, Burcelin R, Gibson G, Jia W, et al. Host-gut microbiota metabolic interactions. Science 2012; 336:1262-7. 


\section{Resumo}

O estudo teve como objetivo analisar a associação entre nascimento por parto cesáreo e adiposidade central em adolescentes em São Luís, Maranhão, Brasil. O estudo de coorte incluiu 601 participantes avaliados ao nascer e com 18-19 anos de idade. Ao nascer, foram avaliados o tipo de parto, escolaridade materna, renda familiar, estado civil materno, índice de massa corporal pré-gestacional, atendimento pré-natal, tabagismo materno, idade gestacional ao nascer e restrição do crescimento intrauterino. Nos adolescentes, a adiposidade central foi avaliada com o método da absorciometria de raios- $X$ de dupla energia. Como indicadores da adiposidade central, foram usadas a razão gordura tronco/gordura total (T/T), razão gordura androide/gordura ginecoide $(A / G)$, razão gordura tronco/ gordura membros $(T / L b)$ e razão gordura tronco/ gordura membros inferiores (T/Lg). Foi desenvolvido um modelo teórico para analisar as associações, usando gráficos acíclicos dirigidos, permitindo a seleção das variáveis que exigiam ajuste mínimo para inclusão no modelo preditivo de exposição ao parto cesáreo. Os dados foram analisados com modelos estruturais marginais, ponderados pelo inverso da probabilidade de seleção. Entre os adolescentes estudados, 38,6\% nasceram de parto cesáreo. Não houve diferença significativa na adiposidade central nos adolescentes nascidos de parto cesáreo, de acordo com os indicadores utilizados: $T / T$ (coeficiente = -0,003; IC95\%: -0,013; 0,007), $A / G$ (coeficiente $=0,001 ;$ IC95\%: $-0,015 ; 0,018)$; $T / L b$ (coeficiente $=-0,016$; IC95\%: $-0,048 ; 0,016$ ); $T / \mathrm{Lg}$ (coeficiente = 0,014; IC95\%: -0,060; 0,030), O estudo conclui que não havia associação entre história de parto cesáreo e aumento de adiposidade central nesse grupo de adolescentes.

Cesárea; Adiposidade; Adolescente

\section{Resumen}

El objetivo de esta investigación fue estudiar la asociación entre el nacimiento por parto con cesárea y la adiposidad central en adolescentes en São Luís, Maranhão, Brasil. La cohorte de estudio incluyó a 601 participantes evaluados en su nacimiento y con 18-19 años de edad. En el momento del nacimiento se evaluó el tipo de parto, educación de la madre, ingresos familiares, estado civil de la madre, indice de masa corporal de la madre, cuidado prenatal, madre fumadora, edad gestacional en el parto y restricción del crecimiento intrauterino. En los adolescentes, la grasa central se evaluó usando el método de absorciometría con rayos $X$ de energía dual. Los indicadores de grasa central utilizados fueron: el cociente de torso-grasa total ( $T / T$ por sus siglas en inglés), el de androide/ginecoide de grasa corporal $(A / G)$, el cociente de masa adiposa torso-extremidades (T/Lb por sus siglas en inglés), y el cociente de masa adiposa torso-pierna ( $T / L g$ por sus siglas en inglés). Se desarrolló un modelo teórico para el estudio de asociaciones, usando grafos acíclicos dirigidos, lo que permitió seleccionar las variables que requerían un mínimo ajuste para su inclusión en el modelo predictivo de exposición al parto por cesárea. Los datos se analizaron con modelos estructurales marginales ponderados por el inverso de la probabilidad de selección. De los adolescentes estudiados, un 38,6\% fueron partos por cesárea. No hubo una diferencia significativa en la adiposidad central de los adolescentes que nacieron por cesárea, según los indicadores usados: $T / T$ (coeficiente $=-0,003$; 95\%CI: -0,013; 0,007), $A / G$ (coeficiente $=0,001$; 95\%CI: -0,015; 0,018); T/Lb (coeficiente $=-0,016$; 95\%CI: -0,048; 0,016); $\mathrm{T} / \mathrm{Lg}$ (coeficiente $=0,014$; 95\%CI: -0,060; 0,030). A modo de conclusión, no hubo asociación entre los partos por cesárea y una mayor adiposidad central en los adolescentes estudiados.

Cesárea; Adiposidad; Adolescente
Submitted on 07/Mar/2020

Final version resubmitted on 15/May/2020

Approved on 16/Jun/2020 